HIDALGO, Luciana. Rio-Paris-Rio. 1. ed. Rio de Janeiro: Rocco, 2016, 159 páginas. ISBN 978-85-325-2989-3.

\title{
RESENHA DE RIO-PARIS-RIO
}

Márcio Alessandro de Oliveira Mestre em Estudos Literários do PPLIN/UERJ.

Num ano de ocupações estudantis em escolas públicas e golpe de Estado, Luciana Hidalgo (1965) proporciona uma prosa de ficção enxuta e de estilo leve, o que é possível não só graças ao contexto social ou apenas à vivência, mas também ao arsenal de temas e formas oferecido pela civilização à artista, cujo trabalho pode retroagir sobre o meio social em que foi concebido.

Na diegese, esgarçada em doze curtos capítulos por um narrador onisciente, Maria de Barros, que mora na Rua Cujas, em Paris, é aluna da Sorbonne e leitora de Descartes. Solitária, vestindo "mantô marrom e calça preta" (HIDALGO, 2016, p. 9), sai de seu quarto "quadrado, minúsculo", que é "cortado por linhas retas" (idem, ibidem, p. 7), e em cujo piso há um X riscado, para ir à faculdade, onde lida com o autoritário professor "ventríloquo" de Filosofia, Monsieur Martin. Embora se veja como "um espírito tropical cartesiano" (p. 10), substitui o indivíduo cartesiano e racional, colocado em xeque na pós-modernidade, pelas próprias emoções: carrega uma forte tensão nervosa em virtude do passado-presente que a assombra e do ligeiro desconforto de ser estrangeira na França de 1968 (curiosamente, o narrador flexiona os verbos no presente do indicativo); ao mesmo tempo, carrega os traços comportamentais construídos na infância com o avô paterno, militar que apoiou o golpe que implementou a ditadura militar no Brasil (a isso se soma o trauma causado pela morte do 
irmão, morte causada por uma arma guardada em casa da família). Tratar-se-ia das identidades contraditórias, presentes não apenas em Maria, mas também no brasileiro Marechal, seu vizinho militante, e Luc, amigo francês e vizinho aristocrata. É graças a Marechal que Maria conhece outras pessoas exiladas, de outras nacionalidades, em virtude das ditaduras de seus países. É Arthur, porém, o brasileiro exilado por quem ela se apaixona, com quem "em poucas horas segue o caminho do sonho" (HIDALGO, 2016, p. 22) e vai ao Marrocos numa viagem que pode muito bem ser imaginária: existe um quê de dúvida em relação ao fantástico, de que fala Tzvetan Todorov (2017, pp.51-7): não é possível confirmar se se trata de um sonho ou de um acontecimento do cronotopo (tempo e espaço descritos na narrativa). Com seu aspecto solar, Arthur representaria o Brasil. Não por acaso a primeira viagem deles é a um deserto (onírico ou não).

Demonstra-se perícia no uso de procedimentos estéticos, os quais talvez aproximem os registros do narrador, intercalados por versos escritos por Arthur, do poema em prosa, o qual, segundo a professora Olga Kempinska (2012, p. 170), foi criado por Aloysius Bertrand, francês pouco conhecido. No excerto abaixo, por exemplo, os pronomes ele e ela formam um dos quiasmos presentes na narrativa (p. 28, destaques nossos):

Ele a olha, ela dorme. Ela acorda, ele levanta. Ela vira para o lado, ele vem. Dois corpos não ocupam o mesmo espaço ao mesmo tempo. Ele ocupa o corpo dela. Ela se ocupa dele. Ele deitado nela, ela montada nele. Ele cochila, ela se vai. Ele a puxa, ela volta. Dois corpos ocupam o mesmo espaço ao mesmo tempo.

O personagem Luc, não obstante sua formação marxista, apresenta um ethos aristocrático, além de um didatismo irritante, que confirma a mathesis (os conhecimentos de que é portador o texto literário). Luc fala da Notre-Dame, "uma obra-prima que mistura 
diferentes estilos, do românico ao gótico" (p. 43), transformada no Templo da Razão em 1793, e também do prédio do Louvre e sua relação com a "barbárie dos vikings" e a Normandia (p. 126). A ser verdade a existência do reducionismo que identifica o conceito de ekphrasis com a descrição pura e simples de seres, objetos e acontecimentos, conforme Álvaro Gomes (2015, p. 20), vemos não só nas "aulas" de Luc, mas também nas descrições do próprio narrador, a confirmação de tal reducionismo, conquanto o romance evidencie que a expressão verbal procura equivaler à expressão não-verbal e visual, tamanha é a perícia da autora no ofício de inocular imagens usando palavras.

O caráter ekphrástico não fica patente apenas na descrição da arquitetura parisiense, mas também no momento em que horror e terror, talvez numa catarse expressionista, por força das circunstâncias, obrigam Maria a fazer as vezes de donzela em perigo que se solta da autorrepressão cartesiana para depois tornar-se uma fera num locus horribilis: as ruas onde "A polícia atacou toda gente que passava e toda gente que passava a atacou de volta" (p. 93), ou seja: as ruas onde explode o Maio de 1968, cujo prenúncio, realizado no pátio da Sorbonne, faz o professor Martin trazer "a expressão do cadáver" (p. 78). É Arthur quem a salva das ruas em que se metera ao seguir o "fantasmático pastor do rebanho" (p. 80), apesar da "inconsistência das pernas que tremem" (idem). Após ser retirada por Arthur do lugar de perigo, em que recebera um corte na testa, ela, que “Nem percebe que ela própria cheira mal, o cheiro azedo do medo" (p. 85), é levada pelo namorado à escuridão sob uma ponte, o Pont Neuf, onde ela "Está fora de si" (p. 85); ele, a seu turno, "É tomado por uma dúvida que não o interrompe, por uma crise de consciência que despreza. Conversa com seus daimons e concordam todos, unânimes, em ir nessa, nela, até o fim" (p. 86), num possível princípio de estupro, a despeito de que "ainda que Arthur quisesse, ela não o 
largaria" (idem) "na caverna/ onde/seres/se bestializam" (idem). Afinal, ele "Nunca ocupou corpo tão vivo" (p. 85). Contudo, admite que "deveria ter parado quando tinha algum controle, quando sentiu o gosto do sangue de Maria escorrer do corte na testa até o pescoço, quando achou que ela ardia em febre e delirava. Tarde, tarde. Arthur também se foi" (p. 86, destaques nossos).

Identifica-se tanto nela quanto nele "a personagem monstruosa e a presença fantasmagórica do passado" (FRANÇA, 2016, p. 2492), elementos precípuos do Gótico literário. Tal passado é a própria ditadura.

Nas páginas 50 e 51, encontram-se palavras de ordem apenas em maiúsculas, num exercício de disposição gráfica que pode surpreender o leitor com uma linguagem "à altura da violência dos acontecimentos históricos" (ROUANET, 1988, p. 77). Uma vez que o universo de Rio-Paris-Rio é habitado "por sujeitos que vivem somente em função do discurso" (BEZERRA, in BAKHTIN, 1981), como Arthur, um poeta, é realçado o jogo polifônico, em que a autoconsciência dos personagens e seus pontos de vista sobre si mesmos e sobre o mundo (cf. BAKHTIN, 1981, p. 39) sempre são registrados pelo narrador, que intercala a consciência de Maria com a de Arthur, conquanto haja apenas um núcleo, o que faz que prevaleça o ponto de vista dela. As alternâncias de consciências e as impressões são exemplificadas pela cena embaixo da ponte, em que diz a si mesmo "foda-se a moral" (p. 85) e dá continuidade ao rito da cópula.

O passado assombra Maria não só quando "a neta do general se lembra da quadrilha de generais mantendo seu país na mira do fuzil" (p. 93), mas também quando tem de lidar com o costume francês relativo às suas origens: o de perguntar sobre a genealogia, 
“remontando se possível ao período medieval, retrocedendo, quem sabe, ao paleolítico" ( $p$. 125).

Após um distanciamento, Arthur retorna à Rua Cujas, onde, "Enquanto ama Maria, fode a neta do general" (p. 153) que tanto colaborou com o regime que Arthur odeia. No último capítulo, Maria, de volta ao Brasil ao lado de Arthur em 1979, admite "que a violência do avô é também a sua violência" (p. 156). Dessa forma, reconhece-se o final já calculado a partir do paralelismo do título: ela saiu do Rio em 1964, foi a Paris e retornou ao Rio: Rio-Paris-Rio. As contradições de Maria e as de Luc podem muito bem ser as do próprio leitor. Como diria Mário Quintana, "somos democratas e escravocratas" (1984, p. 109).

A vivência da autora prevalece como fator condicionante de sentido na medida em que se reconhece que Luciana Hidalgo morou em França, porém a vivência deixa de ser primordial no trabalho de projeção na medida em que impera a assunção de que a ficcionista nem era nascida em 1964, razão por que era muito nova na maior parte do tempo histórico em que inseriu seus personagens. Em tempos de crise política e censuras a exposições de obras de arte, Rio-Paris-Rio não se intimida com o Estado de exceção implementado pelo golpe que derrubou a presidenta Dilma Rousseff; por isso é possível vislumbrar potencial para realizar o efeito almejado pela Escola de Frankfurt: politizar a arte. Se o contexto condiciona o texto literário, este pode retroagir sobre a realidade de que se serve e o condiciona, temor constante entre as autoridades que ainda reproduzem a opressão imposta a artistas.

\section{REFERÊNCIAS}

BARTHES, Roland. Aula. São Paulo: Cultrix, 1980. 
BAKHTIN, Mikhail. Problemas da poética de Dostoiévski. Trad. Paulo Bezerra. Rio de Janeiro: Ed. Forense-Universitária, 1981.

CHKLOVSKI, V. A.. "A arte como procedimento". In: et al.. Teoria da literatura: formalistas russos. Porto Alegre: Editora Globo, 1978, pp. 39-56.

FRANÇA, Julio. "O Gótico e a presença fantasmagórica do passado". In: Anais eletrônicos do XV encontro ABRALIC. Disponível em: < http://www.abralic.org.br/anais/arquivos/2016 1491403232.pdf>. Acesso em: 23/5/2018 (2016). pp. 2492-2502.

GOMES, Álvaro Cardoso. A poesia como pintura. In: . A Ekphrasis em Albano Martins. São Paulo: Ateliê Editorial, FAPESP, 2015.

HIDALGO, Luciana. Rio-Paris-Rio. 1. ed. Rio de Janeiro: Rocco, 2016.

JOST, Fraçois. Uma filosofia das letras. In: COUTINHO, Eduardo F. e FRANCO, Tânia (orgs). Literatura Comparada. Rio de Janeiro: Rocco, 1994, pp. 334-347.

KEMPINSKA, Olga Guerizoli. Aula 22: O poema em prosa. In: et al. Teoria da Literatura I. Rio de Janeiro: Fundação Cecierj, 2012.

ROUANET, Sergio Paulo. Apresentação. In: BENJAMIN, Walter. Origem do drama barroco alemão. Trad. Sergio Rouanet. São Paulo: Brasiliense, 1984.

TODOROV, Tzvetan. Introdução à Literatura Fantástica. Trad. Maria Clara Correa Castello. São Paulo: Perspectiva, 2017.

Artigo recebido em: 20 de abril de 2018. Artigo aprovado em: 16 de maio de 2018. 